\title{
Determinants of Early Postpartum Psychological Reaction among Mothers in Kuala Lumpur Hospital
}

\author{
Ramli $M^{\mathrm{a}}$, Abdullah AAW , Saiful $M M^{\mathrm{b}} \mathrm{B}^{\mathrm{b}}$, Hafiz $\mathrm{MN}^{\mathrm{b}}$ and Fahmi $A A Z^{\mathrm{b}}$ \\ ${ }^{a}$ Kulliyyah of Medicine, International Islamic University Malaysia, Malaysia. \\ ${ }^{b}$ Faculty of Medicine, University of Technology MARA (UiTM), Shah Alam, Malaysia.
}

\begin{abstract}
Introduction: Maternal psychological well-being determines early mother-infant relationship and baby's health. Paying attention on this aspect is essential particularly in early postpartum period. This study aimed to determine early psychological reactions toward socioeconomic profiles, delivery methods and delivery outcomes among postpartum mothers in Kuala Lumpur Hospital. Materials and Methods: A total of 150 twoweek-postpartum mothers participated in this cross sectional study and their psychological perspective was measured by using the Depressive, Anxiety and Stress Scale (DASS). Results: 4\%, 16\% and 4.7\% of respondents had significant depressive, anxiety and stress levels respectively. Conclusion: Socioeconomic variables such household income, level of education and presence of medical illness were statistically significant to determine early postpartum psychological reactions but not the modes or outcomes of delivery.
\end{abstract}

KEYWORDS: Postpartum mothers, socio-economic, depressive, anxiety, stress.

\section{INTRODUCTION}

Any detrimental conditions on the aspect of maternal psychological wellbeing would have long term effects on the emotional and cognitive development for both mothers and their children. ${ }^{1}$ There had been little attention paid to look at an immediate postnatal psychological wellbeing among mothers in relation to their delivery in Malaysia. The agonizing and painful procedures that the mothers have to endure during the childbirth would certainly impose an element of psychological distress. This is particularly pertinent among mothers whose deliveries have to be assisted via instrumental delivery or cesarean operation. Pain, hemorrhage and adjustment to a new responsibility that these mothers have to endure would influence their mood. ${ }^{2}$ This psychological aspect is also compounded by other social factors such as financial difficulties, higher number of children, marital conflict and baby's condition.

Scarce local studies have implicated possible relationships between low socioeconomic group and marital difficulties to postpartum mood changes. ${ }^{3,4}$ A substantial number of studies in the past either internationally or locally were mainly focused on postpartum depression. In this study, we attempted

Corresponding author;

Dr. Ramli Musa

Department of Psychiatry

International Islamic University Malaysia

25000 Kuantan, Pahang, Malaysia

e-mail: ramlidr@yahoo.com to look at an immediate and broader psychological perspective by measuring levels of anxiety, depression and stress and focus on the immediate psychological reactions in relation to their modes of delivery.

The main objective of this study is to explore early psychological changes of postpartum mothers in Hospital Kuala Lumpur in relation to their deliveries and social backgrounds. Difficult deliveries such as Cesarean section and assisted delivery (forceps and vacuum delivery) would certainly impose anxiety and psychological distress to these mothers. Low socioeconomic status (lower income group, low level of education and those with many children) theoretically would result in poorer psychological outcome.

The second objective of this study is to determine whether demographic factors such as ethnicity and marital status would also have influence on the psychological aspect of these mothers.

\section{MATERIALS AND METHODS}

\section{Study Design}

This is a cross sectional study with selection of the subjects was based on stratified quota sampling. The subjects were selected on their presence in the wards during the period of this study. Prior to commencement of this project, a written approval and permission were obtained from the hospital director and ethics committee. 


\section{Procedures}

The nature of study was explained to the subjects and the study proceeded after informed consent was obtained. Demographic data such as age, gender, race, occupation, marital status and mode of delivery were obtained by using a survey form. Levels of anxiety, stress and depression were determined based on the Depression Anxiety Stress Scales (DASS).

\section{Selection of Respondents}

Based on sample size analysis, a total of 140 subjects were required but we managed to recruit 150 patients during the study period. Study population of this study was all mothers in postnatal wards of Hospital Kuala Lumpur including first class wards.

150 mothers with various age, ethnicity and social backgrounds were enrolled in this study by using stratified quota sampling. In the aspect of ethnicity we tried to gather heterogeneous population to reflect the actual Malaysian population. Based on Malaysian Statistic Department (2004) 54.1\% were Malays, 25\% were Chinese, $7.5 \%$ were Indians and $13.2 \%$ from other races. ${ }^{5}$ We used 2 sets of questionnaire. First was demographic questionnaire to measure age, gender, ethnicity and level of education. Second was the Bahasa Malaysia or English version of DASS-21.

Inclusion criteria of the subjects were the mothers' age between 16 to 50 years old; they must be proficient in Bahasa Malaysia or English and within the immediate postpartum period which was determined by 14 days and less. The reason for the last inclusion criteria were due to main objective of this study was to gauge immediate postpartum psychological changes. Subjects who were not able to give informed consent were excluded from the study.

\section{The Depression Anxiety Stress Scales}

Edinburgh Postnatal Depression Scale and Beck Depression Inventory have been validated for its Bahasa Malaysia (BM) versions. ${ }^{6}$ Unfortunately these scales are designed to measure level of depression only. The Depressive Anxiety and Stress Scale (DASS) is a questionnaire that has the ability to gauge 3 psychological aspects. They are depression, anxiety and stress. The DASS has been translated in various languages and validated in many different populations. It is not a diagnostic questionnaire but rather as a severity measurement. ${ }^{7}$ DASS is suitable to be used in any clinical or non-clinical settings. The Bahasa Malaysia version of DASS has been validated and it has excellent reliability and validity. The BM DASS-21 has very good Cronbach's alpha values of $0.84,0.74$ and 0.79 respectively, for depression, anxiety and stress. In addition, it also has good factor loading values for most of its items (.39 to .73$).^{8}$ In measuring immediate psychological reactions toward delivery process, particularly stress and anxiety reactions, DASS would be the appropriate tool to use. The DASS has been used to assess the negative emotional states of, not only depression, but of anxiety and stress in postnatal women.

\section{RESULTS}

Table I. Socio-demographic data

\begin{tabular}{|c|c|c|c|}
\hline & No. & $\%$ & Total \\
\hline \multicolumn{4}{|l|}{ Age } \\
\hline $16-20$ & 11 & 7.3 & \multirow[t]{3}{*}{150} \\
\hline $21-35$ & 125 & 83.3 & \\
\hline $36-45$ & 14 & 9.3 & \\
\hline \multicolumn{4}{|l|}{ Race } \\
\hline Malays & 117 & 78 & \multirow[t]{3}{*}{150} \\
\hline Chinese/others & 18 & 12 & \\
\hline Indians & 15 & 10 & \\
\hline \multicolumn{4}{|l|}{ Marital status } \\
\hline $\begin{array}{l}\text { Married/living together } \\
\text { Divorced/separated }\end{array}$ & $\begin{array}{c}142 \\
7\end{array}$ & $\begin{array}{r}94.7 \\
4.7\end{array}$ & 150 \\
\hline \multicolumn{4}{|l|}{ Household Income } \\
\hline$<$ RM 1000 & 36 & 24 & \multirow[t]{3}{*}{150} \\
\hline RM 1001-5000 & 111 & 74 & \\
\hline$>$ RM 5000 & 3 & 2 & \\
\hline No of Children & 100 & 66.7 & \\
\hline $\begin{array}{l}<3 \\
3 \text { and more }\end{array}$ & 50 & 33.3 & 150 \\
\hline \multicolumn{4}{|l|}{ Levels of Education } \\
\hline Primary school & 13 & 8.7 & \multirow[t]{3}{*}{150} \\
\hline Secondary school & 101 & 67.3 & \\
\hline Tertiary education & 36 & 24 & \\
\hline \multicolumn{4}{|l|}{ Occupation } \\
\hline Housewife & 79 & 52.7 & \multirow[t]{4}{*}{150} \\
\hline Professional & 19 & 12.7 & \\
\hline Semi-skill & 36 & 24 & \\
\hline Labour & 16 & 10.7 & \\
\hline \multicolumn{4}{|l|}{ Mode of Delivery } \\
\hline Normal vaginal & 105 & 70 & \multirow[t]{3}{*}{150} \\
\hline Assisted/Instrument & 3 & 2 & \\
\hline LSCL & 42 & 28 & \\
\hline \multicolumn{4}{|l|}{ Baby's condition } \\
\hline Healthy & 139 & 92.7 & 150 \\
\hline Unhealthy & 11 & 7.3 & \\
\hline
\end{tabular}

Table I summarizes demographic profiles of the subjects. Chinese were obviously underrepresented in this study. Majority were from middle income group, aged between 21 to 35 years old and obtained highest education until secondary school.

Since the development of Bahasa Malaysia DASS was at infancy stage we also analyzed the internal consistency of DASS among these mothers. Cronbach's 
alpha values of $0.81,0.86$ and 0.82 were achieved for depressive, anxiety and stress scales.

Significant Depressive, Anxiety and Stress Levels among Postpartum Mothers

Based on scoring of DASS, 0-9 is normal level for depression, 0-7 for anxiety and 0-14 for stress level, we analyzed that 6 patients (4\%), 24 patients (16\%) and 7 patients $(4.7 \%)$ had significant depressive, anxiety and stress levels respectively.

Table II. Factors Determine Significant Depressive, Anxiety and Stress Levels.

\begin{tabular}{|c|c|c|c|c|c|c|c|}
\hline & $\mathbf{N}$ & $\begin{array}{c}\text { Mean } \\
\text { depressive } \\
\text { Level }\end{array}$ & P value & $\begin{array}{c}\text { Mean } \\
\text { anxiety } \\
\text { level }\end{array}$ & P value & $\begin{array}{l}\text { Mean } \\
\text { stress } \\
\text { level }\end{array}$ & P value \\
\hline \multicolumn{8}{|l|}{ Age } \\
\hline $\begin{array}{l}16-20 \\
21-30 \\
31-45\end{array}$ & $\begin{array}{c}11 \\
125 \\
14\end{array}$ & $\begin{array}{l}3.2 \\
2.2 \\
2.1\end{array}$ & 0.89 & $\begin{array}{l}6.2 \\
4.6 \\
2.2\end{array}$ & $<0.05^{*}$ & $\begin{array}{l}5.7 \\
4.9 \\
2.2\end{array}$ & 0.88 \\
\hline \multicolumn{8}{|l|}{ Race } \\
\hline \begin{tabular}{|l} 
Malays \\
Chinese/other \\
Indians \\
\end{tabular} & $\begin{array}{c}117 \\
18 \\
15\end{array}$ & $\begin{array}{l}2.1 \\
6.3 \\
2.5\end{array}$ & 0.61 & $\begin{array}{l}4.5 \\
5.7 \\
4.2\end{array}$ & 0.44 & $\begin{array}{l}4.7 \\
8.3 \\
5.7\end{array}$ & 0.31 \\
\hline Marital status & 142 & 2.2 & & 4.5 & & 4.8 & \\
\hline $\begin{array}{c}\text { Married/living } \\
\text { together } \\
\text { Divorced/separated }\end{array}$ & 8 & 3.25 & 0.55 & 4.6 & 0.21 & 4.5 & 0.53 \\
\hline \multicolumn{8}{|l|}{ Household income } \\
\hline $\begin{array}{l}<\text { RM } 1000 \\
\text { RM 1001-5000 } \\
>\text { RM 5000 }\end{array}$ & $\begin{array}{c}36 \\
111 \\
3\end{array}$ & $\begin{array}{l}3.8 \\
1.8 \\
0.3\end{array}$ & $<0.05^{*}$ & $\begin{array}{c}5.5 \\
4.3 \\
2\end{array}$ & $<0.05^{*}$ & $\begin{array}{l}6.1 \\
4.4 \\
2.3\end{array}$ & $<0.01^{*}$ \\
\hline No of Children & 100 & 2.4 & & 5.2 & & 5.5 & \\
\hline $\begin{array}{l}<3 \\
3 \text { and more }\end{array}$ & 50 & 2 & 0.38 & 3 & 0.06 & 3.3 & 0.28 \\
\hline \multicolumn{8}{|l|}{ Levels of Education } \\
\hline $\begin{array}{l}\text { Primary school } \\
\text { Secondary school } \\
\text { Tertiary education }\end{array}$ & $\begin{array}{r}13 \\
101 \\
36\end{array}$ & $\begin{array}{l}4.5 \\
2.2 \\
1.64\end{array}$ & $<0.05$ & $\begin{array}{l}4.9 \\
4.3 \\
4.8\end{array}$ & 0.56 & $\begin{array}{l}6.3 \\
4.6 \\
4.7\end{array}$ & 0.53 \\
\hline Occupation & 79 & 2.2 & & 4.3 & & 4.6 & \\
\hline $\begin{array}{l}\text { Housewife } \\
\text { Professional } \\
\text { Semiskilled } \\
\text { Labour }\end{array}$ & $\begin{array}{l}19 \\
36 \\
16\end{array}$ & $\begin{array}{l}1.1 \\
2.3 \\
3.9\end{array}$ & 0.13 & $\begin{array}{l}3.7 \\
4.6 \\
5.8\end{array}$ & 0.43 & $\begin{array}{l}3.8 \\
4.4 \\
7.2\end{array}$ & 0.07 \\
\hline Mode of Delivery & 105 & 2.3 & & 4.5 & & 4.7 & \\
\hline $\begin{array}{l}\text { Normal vaginal } \\
\text { Instrument } \\
\text { LSCL }\end{array}$ & $\begin{array}{c}3 \\
42\end{array}$ & $\begin{array}{l}0.3 \\
2.3\end{array}$ & 0.46 & $\begin{array}{l}4.5 \\
4.6\end{array}$ & 0.65 & $\begin{array}{c}4.3 \\
5\end{array}$ & 0.91 \\
\hline $\begin{array}{l}\text { History of Medical } \\
\text { Disorders }\end{array}$ & 139 & 2.1 & & 4.5 & & 4.5 & \\
\hline $\begin{array}{l}\text { No } \\
\text { Yes }\end{array}$ & 11 & 4.8 & $<0.05^{*}$ & 7.7 & 0.29 & 7.7 & $<0.05^{*}$ \\
\hline Baby's condition & 139 & 2.2 & & 4.5 & & 4.7 & \\
\hline $\begin{array}{l}\text { Healthy } \\
\text { Unhealthy }\end{array}$ & 11 & 3.1 & 0.53 & 4.4 & 0.29 & 5.9 & 0.47 \\
\hline
\end{tabular}

\# Mann-Whitney test $(95 \% \mathrm{Cl})$

Based on table 2, those in younger age group (16-20 years old) were having higher crude means for depressive, anxiety and stress levels, however only anxiety was statistically significant $(p<0.05)$. Low income group was a strong determinant to all psychological aspects $(p<0.01-0.05)$. Those who obtained education until primary school were also had significant higher level of depression. Those with medical history were having significant depressive and stress levels. Other factors such as marital status, ethnicity, mode of delivery and baby's condition did not have significant impact on the immediate postpartum psychological status. 


\section{DISCUSSION}

From a total of 150 respondents, $4 \%$ of them had significant level of depression, $16 \%$ for anxiety and $4.7 \%$ for stress. Looking at the significant level of depression, a comparison with other local study, the figure obtained in this study is much smaller as compared to $9.8 \%$ yielded by Rushidi et al. ${ }^{3}$ Between this study and the study done by Rushidi et al, there were a few similarities in the aspects of ethnicity distribution, level of educational and mode of delivery of the subjects. In comparison with another large population cohort study in overseas, the rate of depression obtained was $5.7 \%$ and anxiety was $2.0 \% .{ }^{9}$ It is worth noting that these discrepancies are due to various reasons. Bear in mind that the tools used in these studies are different. We cannot conclusively say $4.7 \%$ of women obtained in this study were clinically depressed as DASS is not a screening tool for depression. Other aspect is the study period and postpartum timeframe are different from one study to another. Study period for this project is only 2 weeks postpartum which is too short as compared to the latter.

Chinese in this study were glaringly underrepresented. To explain to this polarization, a similar pattern of ethnic distribution was also found in a study done among vacuum deliveries in the Maternity Unit Hospital Kuala Lumpur. ${ }^{10}$ The study found Chinese only contributed $14 \%$ of study population, $58 \%$ Malays and $17 \%$ Indians. Chinese generally are at higher income level and they less utilize government hospitals. Other reason is there was quite significant number of Chinese respondents in this study refused to participate or they were not fluent in either Bahasa Malaysia or English.

A considerable number of studies have consistently shown that the following risk factors were strong predictors of postpartum depression and anxiety. These factors include; history of depression or anxiety during pregnancy, stressful life events, poor social support and a previous history of depression and socio-economic disadvantage. ${ }^{11}$ Other predictors of postpartum depression and blues are maternal low self-esteem, obstetric complications and single marital status. ${ }^{12}$ Based on the results of this study, there were no relationships found between early maternal psychological reactions with regard to their ethnicity, maternal age, level of education, number of children, marital status and delivery events. This finding is aligned with a meta-analyses study of various suitable studies. It failed to find evidence for a significant association between cesarean section and postpartum depression. ${ }^{13}$

From our analysis we found factors that determine significant depressive level are income, level of education and presence of medical illnesses, factors that determine significant anxiety level are only age and income while factors that determine significant stress level are income and medical history. The socioeconomic status of the mother plays a huge role in the mental health of postpartum women especially among level of income. This finding is also in concert with the meta-analysis by O'Hara \& Swain. ${ }^{14}$ They concluded that less family income and lower socio-occupational status indeed were associated with increased risk of maternal stress. The findings suggested that women with fewer financial resources are vulnerable to adverse psychological health. They would certainly benefit from psychological and social services during the period of pregnancy or postpartum..$^{14,15}$ This is a form of primary preventive approach to the problem.

Having identified the risk factors for detrimental postpartum psychological outcomes, a specific attention should be paid to this high risk mothers as postpartum depression and anxiety are proven preventable. ${ }^{16}$ These preventive steps include better antenatal care. ${ }^{17}$

This early psychological reactions is a strong predictive because study in the past showed that there was a strong correlation between maternal mood on a week postpartum to 4 weeks and 8 weeks. ${ }^{18}$ Therefore this early psychological profile could predict intermediate and long term mood pattern. Prospective study looking at the correlation between early mood changes with intermediate outcomes would be worth doing.

Other confounder that the authors feel may influence the psychological outcomes of these mothers is a recent adverse life event. ${ }^{19}$ This aspect was not measured in this study. Paying attention of this factor would require an administration of a specific questionnaire.

\section{Limitations}

Recruitment of the subjects in this study was based on one hospital only and the polarization of these mothers in the aspect of ethnicity was not really reflecting Malaysian population. Hence we may not be able to generalize the findings and conclusion in this study to the general Malaysian population.

\section{CONCLUSION}

Finally, we conclude that socio-economic status of an individual is the most significant factor contributing to the mental health of postpartum women as compared to their delivery events.

\section{Acknowledgements}

We wish to extend our heartfelt gratitude to the Hospital Director of Kuala Lumpur Hospital, Dato' Dr. Zaininah Mohd Zain for her kindness to give permission prior to this study and all doctors at maternity wards for their cooperation. We also would like to express our appreciations to all mothers/patients for their participation and consent. 


\section{REFERENCES}

1. Weinberg MK, Trinick EZ. The impact of maternal psychiatric illness on infant development. J Clin Psychiatry 1998; 59:53-61

2. Goldstein FS, Michal G, Etan ZZ. Catastrophizing labor pain compromises later maternity adjustments. Am J Obstet Gynecol 2005; 192: 826-31

3. Rushidi WM, Shakinah S, Jamil MY. Postpartum depression: A survey of the incidence and associated risk factors among Malay women in Beris Kubor Besar, Bachok, Kelantan. Malays J Med Sci 2002; 9:41-8

4. Samiah Yasmin AK. The Prevalence of postpartum depression and associated factors in district of Kulim, Kedah, Malaysia. Dissertation for Master of Medicine (Family Medicine) Universiti Kebangsaan Malaysia 1998.

5. Department of Statistics, State/District Data Bank, Malaysia; 2005.

6. Rushidi WM, Amir A, Iran H, Mahmood N M. Analysis of the psychometric Properties of the Malay version of Beck Depression Inventoryll (BDI-II) among postpartum women in Kedah, North West of peninsular Malaysia. Malays J Med Sci 2004; 11:19-25

7. Lovibond SH, Lovibond PF. Manual for the Depression Anxiety Stress Scales. Sydney: Psychology Foundation, 1995.

8. Ramli M, Ariff MF, Zaini Z. Translation, validation and psychometric properties of Bahasa Malaysia version of the Depression Anxiety and Stress Scales (DASS). ASEAN J Psychiatry 2007; 8:82-9

9. Coates AO, Schaefer CA, Alexander JL. Detection of postpartum depression and anxiety in a large health plan. J Behav Health Serv Res 2004; 31:117-33

10. Lee HY, Subramanian M, Musa MN. Vacuum delivery at the Maternity Hospital Kuala Lumpur; A comparison between metal and silicone cup. Singapore Med J 1996; 37:55-60

11. Beck CT. State of the Science on postpartum depression: what nurse researchers have contributed? Am J Matern Child Nurs 2008; 33:121-6

12. Beck CT. Predictors of postpartum depression: an update. Nurs Res 2001; 50:275-85

13. Carter FA, Frampton CMA, Mulder RT. Cesarean section and postpartum depression: A review of the evidence examining the link. Psychosom Med 2006; 68:321-30

14. O'Hara, SAM. Rates and risk factors of postpartum depression - a meta-analysis. Int Rev Psychiatry 1996; 8:37-54

15. Warner R, Appleby L, Whitton A, Faraghner B. Demographic and obstetric risk factors for postnatal psychiatric morbidity. Br J Psychiatry 1996; 168:607-11

16. Zlotnick C, Miller IW, Pearlstein T, Howard M, Sweeney P. A Preventive Intervention for Pregnant Women on Public Assistance at Risk for Postpartum Depression. Am J Psychiatry 2006; 163:1443-5

17. Katherine LW, James MP, Kathleen SP, Barbara $\mathrm{HH}$, Catherine MP, Robert L. Prevention of Postpartum Depression: A Pilot Randomized Clinical Trial. Am J Psychiatry 2004; 161:1290-2

18. Abiodun OA. Early postpartum mood as a risk factor for postnatal depression in Nigerian Women. Am J Psychiatry 2006; 163:1435-7

19. Paykel ES, Emms EM, Fletcher J, Rassaby EM. Life events and social support in puerperal depression. Br J Psychiatry 1980; 136:339-46 
